\title{
Effect of handedness on auditory attentional performance in ADHD students
}

This article was published in the following Dove Press journal:

Neuropsychiatric Disease and Treatment

\author{
Sergio L Schmidt ${ }^{1,2}$ \\ Ana Lucia Novais Carvaho 3 \\ Eunice N Simoes ${ }^{2}$ \\ 'Department of Neurophysiology, \\ State University of Rio de Janeiro, \\ Rio de Janeiro, ${ }^{2}$ Neurology \\ Department, Federal University of \\ the State of Rio de Janeiro, Rio de \\ Janeiro, ${ }^{3}$ Department of Psychology, \\ Fluminense Federal University, \\ Niteroi, Brazil
}

\begin{abstract}
The relationship between handedness and attentional performance is poorly understood. Continuous performance tests (CPTs) using visual stimuli are commonly used to assess subjects suffering from attention deficit hyperactivity disorder (ADHD). However, auditory CPTs are considered more useful than visual ones to evaluate classroom attentional problems. A previous study reported that there was a significant effect of handedness on students' performance on a visual CPT. Here, we examined whether handedness would also affect CPT performance using only auditory stimuli. From an initial sample of 337 students, 11 matched pairs were selected. Repeated ANOVAs showed a significant effect of handedness on attentional performance that was exhibited even in the control group. Left-handers made more commission errors than right-handers. The results were interpreted considering that the association between ADHD and handedness reflects that consistent left-handers are less lateralized and have decreased interhemispheric connections. Auditory attentional data suggest that left-handers have problems in the impulsive/hyperactivity domain. In ADHD, clinical therapeutics and rehabilitation must take handedness into account because consistent sinistrals are more impulsive than dextrals. Keywords: attention, ADHD, consistent left-handers, auditory attention, continuous performance test
\end{abstract}

\section{Introduction}

Continuous performance tests (CPTs) are usually used to objectively measure attention performance. ${ }^{1}$ Attention deficit hyperactivity disorder (ADHD) is a highly prevalent disability. ${ }^{2}$ In school settings, ADHD is considered a developmental disability related to learning problems. ${ }^{3}$ The CPTs are commonly used as an auxiliary tool to help establish the diagnosis of ADHD. ${ }^{4}$ Most CPTs employ visual stimuli. However, auditory CPT scores were found to be related to classroom behaviors. ${ }^{5}$ Moreover, auditory and visual CPTs did not show a perfect correlation among their correspondent parameters. ${ }^{6}$ A recent study has shown that handedness affected the performance of a visual CPT. ${ }^{7}$ Despite the crescent interest in auditory CPTs, little is known about the variables that influence CPT performance. To our knowledge, this is the first report of the effect of handedness on an auditory attention test.

Handedness is associated with structural and functional differences between the two hemispheres. Several neuropsychiatric disorders are related to handedness. ${ }^{8}$ Anomalous hemispheric asymmetries have also been reported in ADHD. ${ }^{2}$ However, the relationship between handedness and ADHD has not yet been demonstrated and is still a matter of controversy. ${ }^{9,10}$ Besides anomalous asymmetries, callosal abnormalities have been described in ADHD. ${ }^{11}$ As ADHD has been correlated to both abnormal brain laterality and disrupted interhemispheric connections, the definition of handedness should take
Correspondence: Sergio L Schmidt State University of Rio de Janeiro, 674 Jardim Botanico Street, Room I 18, Rio de Janeiro, RJ, CEP 2246I00, Brazil Tel +55 2l 3204469 l

Email slschmidt@terra.com.br (c) (1) (-) 2017 Schmidt et al. This work is published and licensed by Dove Medical Press Limited. The full terms of this license are available at https://www.dovepress.com/terms.php cc) and incorporate the Creative Commons Attribution - Non Commercial (unported, v3.0) License (http://creativecommons.org//icenses/by-nc/3.0/). By accessing the work you hereby accept the Terms. Non-commercial uses of the work are permitted without any further permission from Dove Medical Press Limited, provided the work is properly attributed. For permission for commercial use of this work, please see paragraphs 4.2 and 5 of our Terms (https://www.dovepress.com/terms.php). 
into account the strength of the cerebral asymmetries and the efficiency of interhemispheric connections. The strength is associated with the direction of handedness since left-handers are known to be less lateralized than right-handers. ${ }^{12}$ Consistency of handedness is related to the efficiency of callosal connections, because consistent handers show decreased right hemisphere activation. ${ }^{13}$

Here, we examined a possible relationship between handedness (direction and consistency) and auditory CPT variables. It is hypothesized that consistently left-handed subjects will show impairments in attentional performance because they are less lateralized and exhibit decreased interhemispheric connections.

\section{Methods}

Participants were recruited from elementary schools. The ethical review committee of State University of Rio de Janeiro (UERJ) approved the research protocol. The participants' participation in the research was voluntary. The school principals and the parents or legal guardians of the children provided signed written informed consents for this study.

Handedness was assessed by direct observation of three tasks: 1) hand to write, 2) hand to take a sheet of paper on the table, and 3) hand to open a lid of a bottle. Each participant was classified as right consistent, left consistent, or nonconsistent. To be consistent, the student had to perform the three tasks with the same hand.

The DSM-5 criteria were used during the clinical interview to identify students with ADHD. ${ }^{14}$ Furthermore, the teachers completed a standardized checklist composed of questions that are rated on a scale reflecting behavioral problems. The classification of the children also took into account qualitative information on behavioral problems provided by the teachers. Therefore, a child was included in the ADHD group if there were not any discrepancies among the qualitative observation by the teacher, the rating scale, and the clinical interview. Children with epilepsy, previous history of traumatic brain injury, psychosis, mood disorders, learning disabilities (including dyslexia, dysgraphia, and dyscalculia), or taking any kind of medication were excluded from the study. The control group was composed of children who did not present any behavioral problem.

Attentional performance was examined through the Continuous Auditory Attention Test (CAAT). The subjects were required to press the computer spacebar as soon as specific auditory target stimuli were heard. The hand used to perform the task was the same hand used to write. The participants listened to the recorded voice via a headphone. They performed the test individually. For each child, the loudness of the voice was checked to make sure that the subject could comfortably hear the sound. There were six blocks, with three sub-blocks each of 20 trials (syllable considered target and another syllable as nontarget). The parameters of the test included omission errors (OEs), commission errors (CEs), reaction time of correct responses (RTs), and variability of reaction time (VRT).

Initial sample included 337 students. From this sample, 22 students (11 consistent right-handed and 11 consistent left-handed) were chosen to participate (mean age $=12.42$ years, $\mathrm{SD}=3.20$ years).

For each parameter of the CAAT, repeated ANOVAs were performed considering "handedness" as the repeated within-subjects factor (right vs left) and "disease" (control vs ADHD) as the between-subjects factor. The null hypothesis (absence of difference) was tested against the hypothesis of a deficit in attention performance in consistent left-handers (CLHs). The significance level was set $5 \%$, one tailed. For those parameters of the CAAT in which the repeated ANOVAs showed a significant handedness effect or a significant interaction, post hoc comparisons were performed using pairwise Student's $t$-tests and Bonferroni's correction when needed.

This study used the matched-subject instead of the withinsubject design because this design allows a smaller number of participants. The formula for the sample size $(\mathrm{Np})$ required to compare pairwise difference is

$$
N p=\left\{\frac{(Z \alpha / 2+Z \beta) \cdot \sigma}{D}\right\}^{2}
$$

where $\alpha=$ Type I error, for $\alpha=0.05, Z \alpha / 2=1.96$; $\beta=$ Type II error, for $\beta=0.20, Z \beta=0.84$ (power $=1-\beta=0.80$ ); $\sigma=$ common standard deviation (based on a previous test-retest reliability study with 50 subjects); and $\mathrm{D}=$ minimum difference accepted.

Considering differences (D) that are psychologically meaningful, we found a minimum of six subjects for the pairwise comparisons between left- and right-handers.

\section{Results}

The sample included 22 subjects drawn from the whole sample. The selection was designed to match gender, age, disease, and handedness. Eight children fulfilled the DSM-5 criteria for ADHD (four left-handed and four right-handed). It should be mentioned that the subjects were selected not simply by showing left-hand preference ( $10 \%$ of the population), but also by being CLHs (just $<5 \%$ of the population). Therefore, considering the whole sample, the number of 
CLH participants was 17 . Among these 17 CLH subjects, 11 completed all procedures. From the 150 consistent right-handed subjects, we randomly paired 11 consistent right-handers (CRHs) with the 11 CLHs (same age, gender, and presence/absence of ADHD).

Repeated ANOVAs showed a significant effect of handedness for $\mathrm{CE}(F=4.50, d f=1 / 9, P=0.031)$. There was no significant handedness effect for RT $(F=0.16, d f=1 / 9, P>30 \%)$, OE $(F=0.13, d f=1 / 9, P>30 \%)$ and VRT $(F=0.08, d f=1 / 9$, $P>30 \%)$. Interaction between handedness and disease did not reach significance for all parameters of the CAAT.

The effect of handedness on CE is explained by the higher number of errors in CLHs as compared to CRHs (Figure 1). The interaction (handedness $\times$ disease) did not reach significance because the CE percentage difference between the two groups (ADHD and control) was very similar.

\section{Discussion}

The present data suggest that consistently left-handed subjects show greater problems with the CPT performance compared to right-handed subjects. This result may reflect the fact that left-handers show less hemispheric asymmetries than right-handers and that consistent handers show less interhemispheric interactions than nonconsistent handers. It is known that a significant number of left-handers do not exhibit normal patterns of brain asymmetries, and these are needed for the neural processing of attention. ${ }^{12,15}$ Moreover, the CPT task engages the two cerebral hemispheres in an asymmetrical way. ${ }^{16}$ The effect of consistency of handedness may reflect that more consistent hand preference is associated with smaller corpus callosum size and decreased right hemisphere activation. ${ }^{13}$ Our data suggest that the need for interhemispheric interaction may be especially necessary for subjects with less hemispheric asymmetry.

In studies involving left-handers, limitations such as small sample sizes and heterogeneity among left-handers are some of the many that may appear. In this study, a matched pairs design and a reliable task were used to overcome the small number of consistent left-handed subjects. Using a matched pairs design and the available norms for the auditory task, we calculated the minimum number of subjects to find a difference which has a clinical meaning for each one of the parameters of the test. A similar approach was recently published in fibromyalgia patients. ${ }^{17}$ Apart from the great

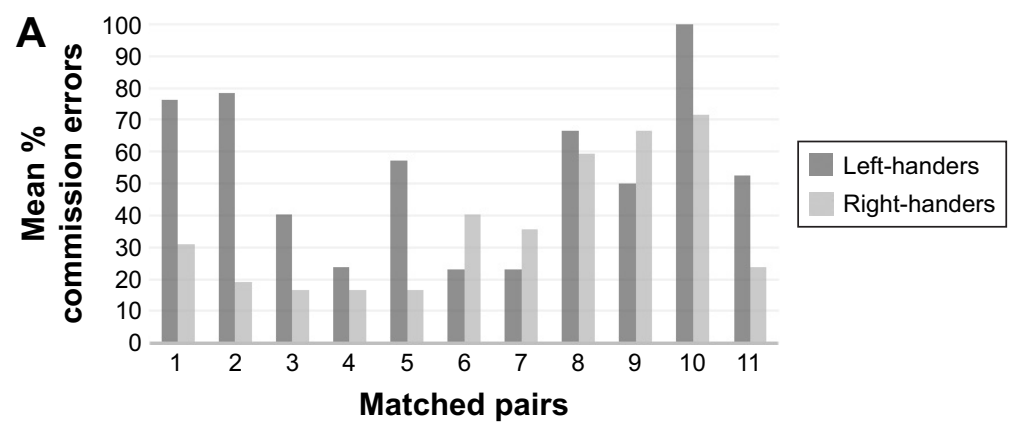

B

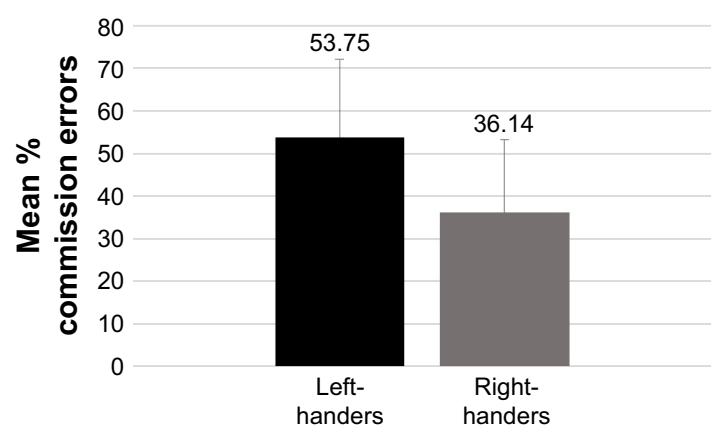

C

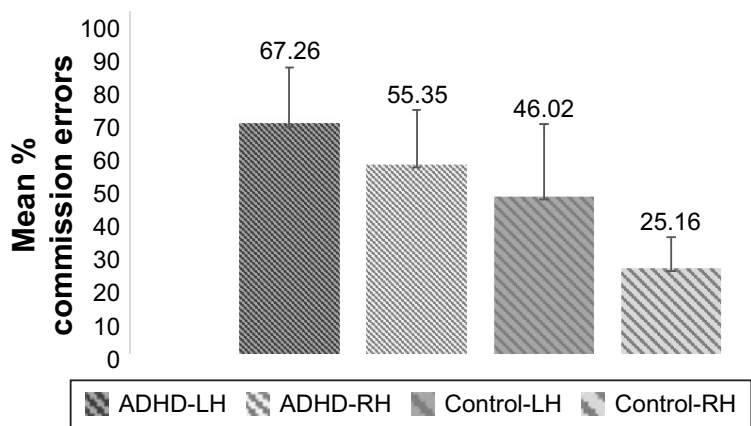

Figure I Effect of handedness on performance of the CVAT.

Notes: (A) The percentage of commission errors made by left- and right-handers is shown for each one of the II matched pairs. Note that the percentage of commission errors is higher in left-handers compared to right-handers in $\mathbf{8}$ out of II matched pairs. Values are the percentage of commission errors (number of errors/total number of incorrect targets) made by each subject. (B) The means of the percentage of commission errors differ significantly between right- and left-handers. Note that left-handers make more commission errors than right-handers. Values are means and bars are standard errors. (C) Consistent left-handers with ADHD make the greatest number of commission errors, while right-handers in the comparison group make the lowest numbers of errors. The presence of ADHD increases the number of commission errors in both right- and left-handers. However, the difference between right- and left-handers is also exhibited by right- and left-handers in the normal group. Values are means of the raw percentage scores; lines are standard errors of the means.

Abbreviations: CVAT, continuous visual attention test; ADHD, attention deficit hyperactivity disorder; LH, left-handers; RH, right-handers. 
reliability of the CPT, the use of a paired design allowed us to use a small sample size. Sometimes a small difference in a big sample may reach statistical significance but may not show clinical significance. Here, although the sample was small, the results reached statistical and clinical significance, being then, relevant for clinical purposes.

One possible interpretation of the lack of interaction between handedness and disease was the small sample size. However, both control and ADHD groups showed an expressive handedness effect for the parameter of the task. Lefthanders were found to be more impulsive than right-handers, and the presence of ADHD did not influence the result once the same proportional difference was already found in the control group by itself. Recently, we found the same results for the visual task using a larger sample size. ${ }^{7}$

The handedness effect was found only for CE. CEs are viewed as a measure of impulsivity. Hardier and Wright suggest that behavioral inhibition is linked to consistency of handedness in left-handers. ${ }^{18}$ Our findings indicate that impulsiveness may be dependent on the direction and consistency of handedness. Therefore, in ADHD students clinical therapeutics and rehabilitation must take handedness into account. Further investigations should use more standard lateralization tests.

\section{Acknowledgments}

The authors are thankful to Catarina S Padilla for the critical comments on the manuscript. Alex C Manhaes and Sergio L Schmidt developed the CAAT used in this study.

\section{Disclosure}

The authors report no conflicts of interest in this work.

\section{References}

1. Ogg RJ, Zou P, Allen DN, Hutchins SB, Dutkiewicz RM, Mulhern RK. Neural correlates of a clinical continuous performance test. Magn Reson Imaging. 2008;26(4):504-512.

2. Cortese S. The neurobiology and genetics of Attention-Deficit/ Hyperactivity Disorder (ADHD): what every clinician should know. Eur J Paediatr Neurol. 2012;16(5):422-433.
3. Imeraj L, Antrop I, Sonuga-Barke E, Deboutte D, Deschepper E, Bal S, Roeyers H. The impact of instructional context on classroom on-task behaviour: a matched comparison of children with ADHD and nonADHD classmates. J Sch Psychol. 2013;51(4):487-498.

4. Epstein JN, Erkanli A, Conners CK, Klaric J, Costello JE, Angold A. Relations between continuous performance test performance measures and ADHD behaviors. J Abnorm Child Pshychol. 2003;31(5): 543-554.

5. Lehman EB, Olson VA, Aquilino SA, Hall LC. Auditory and visual continuous performance tests-relationships with age, gender, cognitive functioning, and classroom behavior. Journal of Psychoeducational Assessment. 2006;24(1):36-51.

6. Schmidt SL, Simões EN, Novais Carvalho AL. Association between auditory and visual continuous performance tests in students with ADHD. J Atten Disord. Epub 2016 Nov 18.

7. Simões EN, Carvalho ALN, Schmidt SL. What does handedness reveal about ADHD? An analysis based on CPT performance. Res Dev Disabil. 2017;65:46-56.

8. Brandler WM, Paracchini S. The genetic relationship between handedness and neurodevelopmental disorders. Trends Mol Med. 2014; 20(2):83-90.

9. Ghanizadeh A. Lack of association of handedness with inattention and hyperactivity symptoms in ADHD. J Atten Disord. 2013;17(4): 302-307.

10. Rodriguez A, Kaakinen M, Moilanen I, Taanila A, McGough JL, Loo S, Järvelin MR. Mixed-handedness is linked to mental health problems in children and adolescents. Pediatrics. 2010;125(2):e340-e348.

11. Gilliam M, Stockman M, Malek M, et al. Developmental trajectories of the corpus callosum in attention-deficit/hyperactivity disorder. Biol Psychiatry. 2011;69(9):839-846.

12. Corballis MC. Left brain, right brain: facts and fantasies. PLoS Biol. 2014;12(1):e1001767.

13. Propper RE, Pierce J, Geisler MW, Christman SD, Bellorado N. Hemispheric asymmetry in frontal EEG: Inconsistent-right-handers are more right hemisphere active. Open Journal of Medical Psychology. 2012;1(4):86-90.

14. American Psychiatric Association. Diagnostic and Statistical Manual of Mental Disorders, Fifth Edition (DSM-5). Washington, DC: American Psychiatric Association; 2013.

15. Chiang HL, Chen YJ, Lo YC, Tseng WY, Gau SS. Altered white matter tract property related to impaired focused attention, sustained attention, cognitive impulsivity and vigilance in attention-deficit/hyperactivity disorder. J Psychiatry Neurosci. 2015;40(5):325-335.

16. Schmidt SL, Correa PL, Tolentino JC, et al. Value of combining activated brain FDG-PET and cardiac MIBG for the differential diagnosis of dementia. Differentiation of dementia with Lewy Bodies and Alzheimer Disease when the diagnoses based on clinical and neuroimaging criteria are difficult. Clin Nucl Med. 2008;33(6):398-401.

17. Schmidt G, Alvarenga R, Manhães A, Schmidt S. Attentional performance may help to identify duloxetine responders in chronic pain fibromyalgia patients. Eur J Pain. 2017;21(6):977-986.

18. Hardier SM, Wright L. Differences between left- and right-handers in approach/avoidance motivation: influence of consistency of handedness measures. Front Psychol. 2014;5:134.
Neuropsychiatric Disease and Treatment

\section{Publish your work in this journal}

Neuropsychiatric Disease and Treatment is an international, peerreviewed journal of clinical therapeutics and pharmacology focusing on concise rapid reporting of clinical or pre-clinical studies on a range of neuropsychiatric and neurological disorders. This journal is indexed on PubMed Central, the 'PsycINFO' database and CAS,

\section{Dovepress}

and is the official journal of The International Neuropsychiatric Association (INA). The manuscript management system is completely online and includes a very quick and fair peer-review system, which is all easy to use. Visit http://www.dovepress.com/testimonials.php to read real quotes from published authors. 